\title{
Analytical Study of Vapour Compression Refrigeration System Using Diffuser and Subcooling
}

\author{
NeerajUpadhyay \\ UG Student, Mechanical Engineering Department, ShriRamswaroop Memorial Group Of Professional \\ Colleges, Lucknow.
}

\begin{abstract}
This Paper Presents The Concept Of Analytical Study Ofvapour Compression Refrigeration System Using Diffuser And Subcoolingmainly Carried Out To Improve The Coefficient Of Performance Of System. To Improve The Coefficient Of Performance, It Is To Required That Compressor Work Should Decrease And Refrigerating Effect Should Increase. Initially The Diffuser Of Increasing Cross-Sectional Area Profile Was Designed, Fabricated And Introduced In Our VCR Apparatus. The Size Of Diffuser Selected Was Of 15 Degree Divergence Angle. . By Using Diffuser Power Consumption Is Less For Same Refrigerating Effect So Performance Is Improved. The Size Of The Condenser Can Also Be Reduced Due To More Heat Transfer. So Cost Of The Condenser Will Be Reduced.The Parameters Pressure And Temperature Were Measured. After Result Analysis, We Have Found That The COP Was Enhanced From2.65 To 3.38 In The Case When Conventional VCR System Was Used With Diffuser.
\end{abstract}

Keywords: VCR System, COP, Diffuser, Sub-cooling, Divergence angle.

\section{INTRODUCTION}

Refrigeration may be defined as lowering the temperature of an enclosed space by removing heat from that space and transferring it elsewhere. The most frequently used refrigeration cycle is the vapor compression refrigeration cycle. Ideal vapor compression refrigeration cycle results, by eliminating impracticalities associated with reversed Carnot cycle such as vaporizing the refrigerant completely before compression, replacing turbine with throttling device (expansion valve or capillary tube). Generally, domestic and industrial refrigerator, air conditioning system, heat pump and water cooler designed based on vapor compression refrigeration cycle.

In 1805, the American inventor Oliver Evans [1] described a closed vapor-compression refrigeration cycle for the production of ice by ether under vacuum. Heat would be removed from the environment by recycling vaporized refrigerant, where it would move through a compressor and condenser and would eventually revert to a liquid form in order to repeat the refrigeration process over again.

Yari et al. [2] developed a new configuration of the ejector-vapour compression refrigeration cycle, which used an internal heat exchanger and intercooler to enhance the performance of the cycle.Results obtained showed that there were increase of $8.6 \%$ and $8.15 \%$ in coefficient of performance and second law efficiency values respectively of the new ejector-vapour compression refrigeration cycle as compared to the conventional ejector-vapour compression refrigeration cycle with R125. It was also found that there was increase of $21 \%$ in the coefficient of performance of the new ejector-vapour compression cycle compare to the conventional vapour compression system.

Selvaraju et al. [3] analyzed an ejector with environment friendly refrigerants. Vapour ejector refrigeration is a heat-operated system utilizing low-grade energy such as solar energy, waste heat from industrial processes, etc., and it could satisfactorily be operated at generator temperature as low as 650C. Results obtained were showed that among the working fluids selected, R134a given a better performance and higher critical entrainment ratio in comparison with other refrigerants.

Bergander [4] investigated new regenerative cycle for vapour compression refrigeration which described a novel approach to the Rankine vapour compression cycle for cooling and refrigeration. Results obtained were showed that pressure on the ejector increased by 15-16\% and prototype achieved energy saving of $16 \%$.

Akintunde [5] obtained the validation of a design model for vapour compression refrigeration system developed by Akintunde [6]. This model was used to design a vapour compression refrigeration system. The experimental set-up was made up of a compressor- reciprocating type, $0.746 \mathrm{~kW}$ capacity, using R134a as working fluid, with cylinder stroke volume of $32.7 \mathrm{~cm} 2$, evaporator and condenser, bare coil tube-in-tube serpentine copper coil. The analysis showed that the model results were comparable to the actual system from both quantitative and qualitative points of view. Under the same operational conditions, maximum absolute deviations of the variable 
parameters - mass flow rate, coefficient of performance and circulating water temperature were within the range of $16 \%$.

Jianlin Yu, Hua Zhao, Yanzhong Li [7] Presented a novel auto cascade refrigeration cycle (NARC) with an ejector. In the NARC, the ejector is used to recover some available work to increase the compressor suction pressure. The NARC enables the compressor to operate at lower pressure ratio, which in turn improves the cycle performance.

Yinhai Zhu and Peixue Jiang [8] developed a refrigeration system which combines a basic vapor compression refrigeration cycle with an ejector cooling cycle. The ejector cooling cycle is driven by the waste heat from the condenser in the vapor compression refrigeration cycle. The additional cooling capacity from the ejector cycle is directly input into the evaporator of the vapor compression refrigeration cycle the system analysis shows that this refrigeration system can effectively improve the COP by the ejector cycle with the refrigerant which has high compressor discharge temperature.

N.D. Banker, P. Dutta, M. Prasad and K. Srinivasan [9] present the results of an investigation on the efficacy of hybrid compression process for refrigerant HFC R134a in cooling applications. The conventional mechanical compression is supplemented by thermal compression using a string of adsorption compressors. It is shown that almost $40 \%$ energy saving is realizable by carrying out a part of the compression in a thermal compressor compared to the case when the entire compression is carried out in a single-stage mechanical compressor. The hybrid compression is feasible even when low grade heat is available. Some performance indicators are defined and evaluated for various configurations.

Andrea Chesi, Giovanni Ferrara, Lorenzo Ferrari and Fabio Tarani [10] analyzed a complex system in which the solar powered ejection machine is used to increase the efficiency of a traditional vapor compression machine by subtracting heat from the condenser. By means of a transient analysis, performed with a reference building and with climate data corresponding to four different system locations worldwide, the year-round performance of such a system in a space cooling application is estimated in terms of energy balance and savings on power costs with respect to the traditional solutions

A. Selvaraju and A. Mani [11] investigate the experimental analysis of the performance of a vapor ejector refrigeration system. The system uses R134a as working fluid and has a rated cooling capacity of 0.5 $\mathrm{kW}$. The influence of generator, evaporator and condenser temperatures on the system performance is studied. For a given ejector configuration, there exists an optimum temperature of primary vapor at a particular condenser and evaporating temperatures, which yields maximum entrainment ratio and COP.

L. Kairouani, M. Elakhdar, E. Nehdi and N. Bouaziz [12] presented an improved cooling cycle for a conventional multi-evaporators simple compression system utilizing ejector for vapourprecompression is analyzed. The ejector enhanced refrigeration cycle consists of multi-evaporators that operate at different pressure and temperature levels. A one-dimensional mathematical model of the ejector was developed using the equations governing the flow and thermodynamics based on the constant-area ejector flow model. The theoretical results show that the COP of the novel cycle is better than the conventional system.

Advances in condenser to increase coefficient of performance means to increase degree of sub-cooling, F. W. $\mathrm{Yu}$ and K. T. Chan [13] described use of direct evaporative coolers to improve the energy efficiency of aircooled condenser. This evaporative cooler is installed in front of air-cooled condenser to pre-cool outdoor air before entering the condenser. Results were predicted that the use of the evaporative cooler results in an increase in the refrigeration effect.

Present work deals with the improvement of vapor compression refrigeration system by using subcooling and diffuser at inlet of condenser.In this work, diffuser is installed at condenser inlet. In vapour compression refrigeration system, condenser is used to remove heat from high pressure vapour refrigerant and converts it into high pressure liquid refrigerant. The refrigerant flows inside the coils of condenser and cooling fluid flows over the condenser coils. Condenser used in domestic vapour compression refrigeration system is air cooled condenser, which may be naturally or forced aircooled. Heat transfer occurs from the refrigerant to the cooling fluid. High pressure liquid refrigerant flows through an expansion device to obtain low pressure refrigerant. Low pressure refrigerant flows through the evaporator. Liquid refrigerant in the evaporator absorbs latent heat and get converted into vapour refrigerant which returns to compressor. Compressor raises the pressure and temperature of the vapour refrigerant and discharges it into the condenser to complete the cycle[14,15].In the present cycle, the vapor refrigerant leaves the compressor with comparatively high velocity. This high velocity refrigerant directly impinges on the tubing of condenser which may cause damage to it by vibration, pitting or erosion. It results in undesirable splashing of refrigerant in the condenser coil. It also results a phenomenon called as "liquid hump". Liquid hump refers to a rise in the level of the condensed refrigerant liquid in the central portion of the condenser as compared to the level at the ends of the condenser. It reduces the effective heat transfer surface area which can reduce condenser efficiency. Diffuser is the static device. It raises the pressure of flowing fluid by converting its kinetic energy. In vapor compression refrigeration system, to avoid the problems of high velocity refrigerant one of the way is to use diffuser at condenser inlet. It smoothly 
decelerates the incoming refrigerant flow achieving minimum stagnation pressure losses and maximizes static pressure recovery[16]. Due to pressure recovery, at same refrigerating effect compressor has to do less work. Hence, power consumption of the compressor will be reduced which results improvement in system efficiency. As the refrigerant flow passes through the diffuser, pressure as well as temperature will be increased. In air cooled condenser for constant air temperature, temperature difference between hot and cold fluid will be increased. So, amount of heat rejected from condenser will be increased. To remove the same amount of heat less heat transfer area will be required. Using the diffuser at condenser inlet will provides an opportunity to use smaller condenser to achieve the same system efficiency. Use of diffuser will also provide an advantage of reducing the effect of starvation in vapor compression refrigeration systems[17].

The cross-sectional area of diffuser should reduce in the flow direction for supersonic flows and should increase for subsonic flows [16]. The velocity of refrigerant leaving the compressor is sub-sonic. Hence, crosssectional area of diffuser should be increasing.

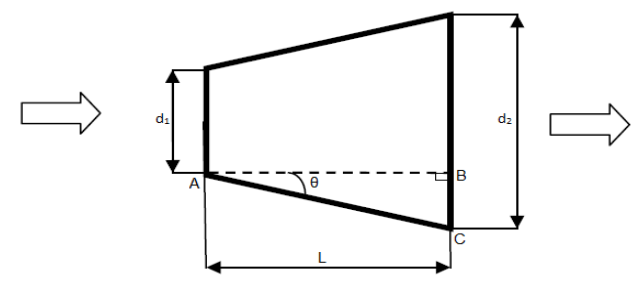

Figure1: Geometry of diffuser

Diffuser's inlet and outlet diameters were designed. To design length of diffuser equation is developed from Figure.

$$
\mathrm{L}=\mathrm{AB}=\frac{\left(\mathrm{d}_{2-\mathrm{d}_{1}}\right) / 2}{\tan \theta}
$$

\section{Methodology}

The schematic diagram of the vapour compression refrigeration system with diffuser at condenser inlet is shown in figure 2. The systemconsists of two flow lines one is simple VCRSflow line without diffuser and other is flow line with diffuser. Two pressure gauges are installed at diffuser outlet and at simple flow line to measure the pressure of the refrigerant at diffuser outlet and pressure in simple VCRS flow line. Thus we can calculate the pressure with and without diffuser. A fan is introduced to condenser for the subcooling effect. The both lines can be opened or closed with the help of flow control valves. A constant refrigeration effect is maintained throughout the experiment.The experiment is performed by taking readings with and without diffuser and compared with each other.

P-h diagram has been shown in figure 3 .

Figure 4 shows the actual set up where the experiment is carried out.

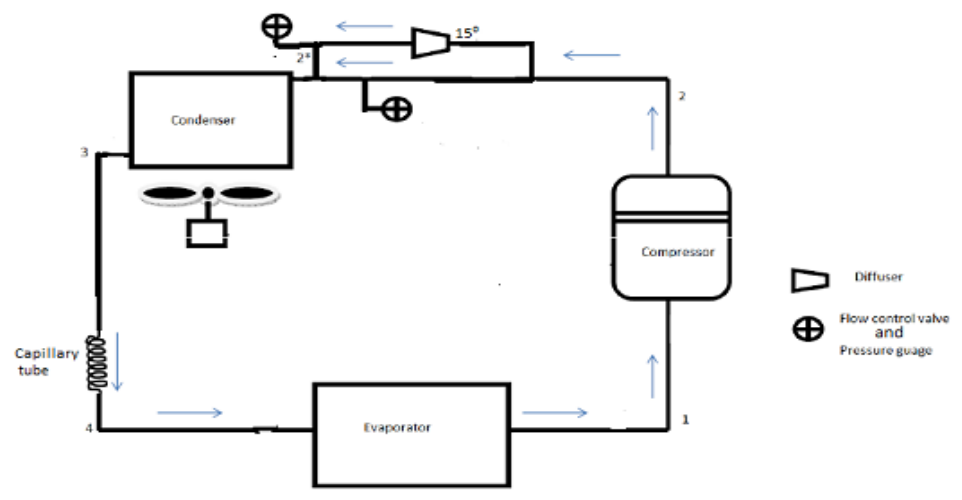

Figure 2 : Schematic of vapour compression refrigeration system with diffuser at condenser inlet 


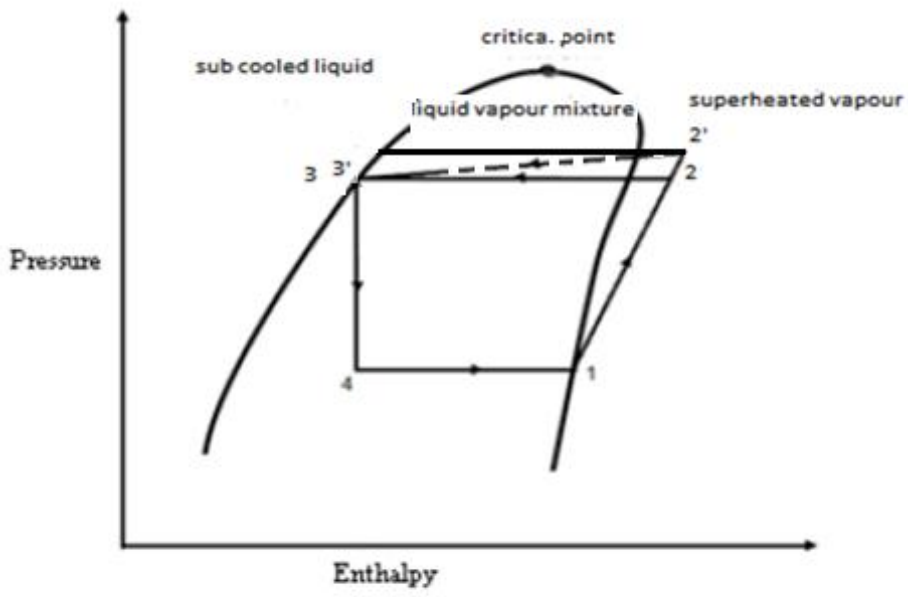

Figure 3: Pressure-Enthalpy chart

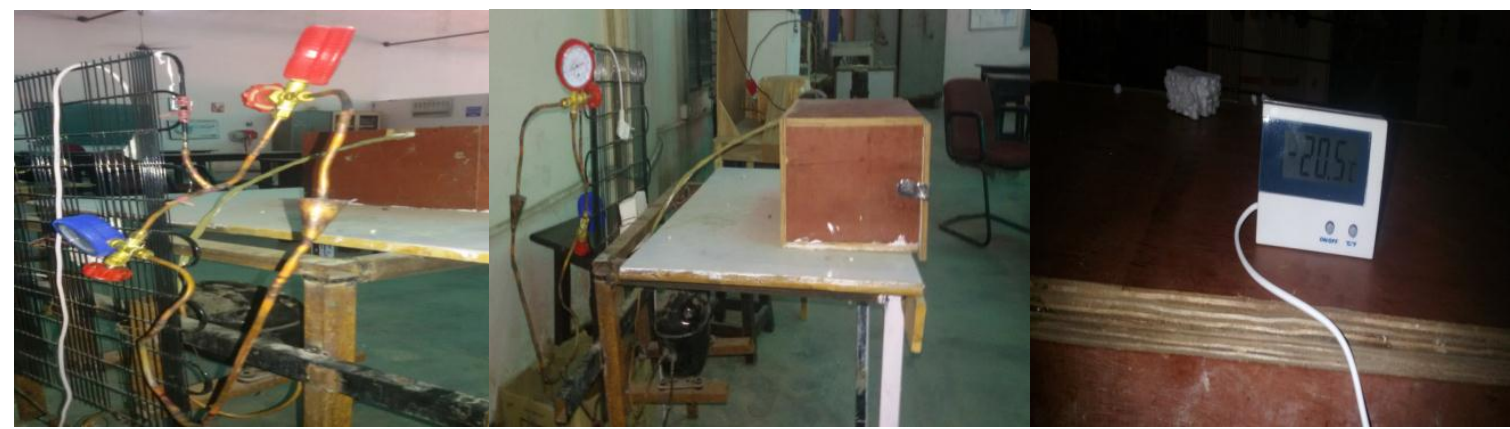

Figure 4 :Experimental setup

Figure 3 shows the pressure enthalpy chart of the system. The path 1-2-3-4 shows the VCR cycle without diffuser and path 1-2'-3'-4 shows the VCR cycle with diffuser at condenser inlet.

$\mathrm{COP}=$ net refrigerating effect $/$ workdone

$=(h 1-h 4) /(h 2-h 1)$

$\mathrm{COP}($ when diffuser is not used $)=$ net refrigerating effect $/$ workdone

$=(h 1-h 4) /\left(h 2^{\prime}-h 1\right)$

After the use of diffuser the pressure will decrease from point 2 ' to 2 .

So the cop willbecome:

$\operatorname{COP}($ when diffuser is used $)=(\mathrm{h} 1-\mathrm{h} 4) /(\mathrm{h} 2-\mathrm{h} 1)$

so the COP will increase by the factor $=\{(\mathrm{h} 1-\mathrm{h} 4) /(\mathrm{h} 2-\mathrm{h} 1)\}-\left\{(\mathrm{h} 1-\mathrm{h} 4) /\left(\mathrm{h} 2^{\prime}-\mathrm{h} 1\right)\right\}$

\section{Without Diffuser:}

\section{Results}

Condenser Pressure $=140$ psi;Condenser Temperature $=38.3$ degrees Celsius; Evaporator Pressure $=17$ psi;Evaporator Temperature $=-22$ degrees Celsius; $\mathrm{h} 1=587.8 \mathrm{KJ} / \mathrm{Kg} ; \mathrm{h} 2=637.8 \mathrm{KJ} / \mathrm{Kg} ; \mathrm{h} 3=455$ $\mathrm{KJ} / \mathrm{Kg}$;Refrigerating Effect $=132.8 \mathrm{KJ} / \mathrm{Kg}$;

Rate of heat rejection from Condenser $=182.8 \mathrm{KJ} / \mathrm{Kg}$;

Compressor Power Output $=50.0 \mathrm{KJ} / \mathrm{Kg}$;

Coefficient of Performance $=2.656756$

\section{With Diffuser}

Condenser Pressure $=160$ psi;Condenser Temperature $=43.4$ degrees Celsius; Evaporator Pressure $=17$ psi;Evaporator Temperature $=-22$ degrees Celsius; 1 1 $=587.8 \mathrm{KJ} / \mathrm{Kg} ; \mathrm{h}^{\prime}{ }^{\prime}=648.6 \mathrm{KJ} / \mathrm{Kg} ; \mathrm{h} 3{ }^{\prime}=455$ $\mathrm{KJ} / \mathrm{Kg}$;Refrigerating Effect $=132.8 \mathrm{KJ} / \mathrm{Kg}$;

Rate of heat rejection from Condenser $=193.6 \mathrm{KJ} / \mathrm{Kg}$;

Compressor Power Output $=50.0 \mathrm{KJ} / \mathrm{Kg}$;

Coefficient of Performance $=3.389657$ 
Increase in $\mathrm{COP}=3.389657-2.656756=0.732901$

$\%$ increase in $\mathrm{COP}=(0.732901 / 2.656756) * 100$

$$
=27.58 \% \text {. }
$$

Table 1 :Temperature and pressure of refrigerant at various state points

\begin{tabular}{|c|c|c|c|c|c|}
\hline $\begin{array}{l}\text { State } \\
\text { points }\end{array}$ & Position & $\begin{array}{l}\text { Temperature } \\
\text { without } \\
\text { diffuser (in } \\
\text { degree C) }\end{array}$ & $\begin{array}{l}\text { Temperatur } \\
\text { e with } \\
\text { diffuser (in } \\
\text { degree } \mathrm{C} \text { ) }\end{array}$ & $\begin{array}{l}\text { Pressure } \\
\text { without } \\
\text { diffuser (in psi) }\end{array}$ & $\begin{array}{l}\text { Pressure with diffuser of } 15 \text { degree } \\
\text { divergence angle (in psi) }\end{array}$ \\
\hline 2 & $\begin{array}{l}\text { Condenser } \\
\text { inlet }\end{array}$ & 38.3 & 43.4 & 140 & 160 \\
\hline 4 & $\begin{array}{l}\text { Evaporator } \\
\text { Inlet }\end{array}$ & -22.1 & -22.1 & 17 & 17 \\
\hline
\end{tabular}

Table 1 summarizes temperature and pressure of refrigerant measured at various state points shown in Figure 2 and Figure 3.

Table 2 :Refrigerating effect,compressor power input, COP, and heat rejection rate without and with diffuser condition

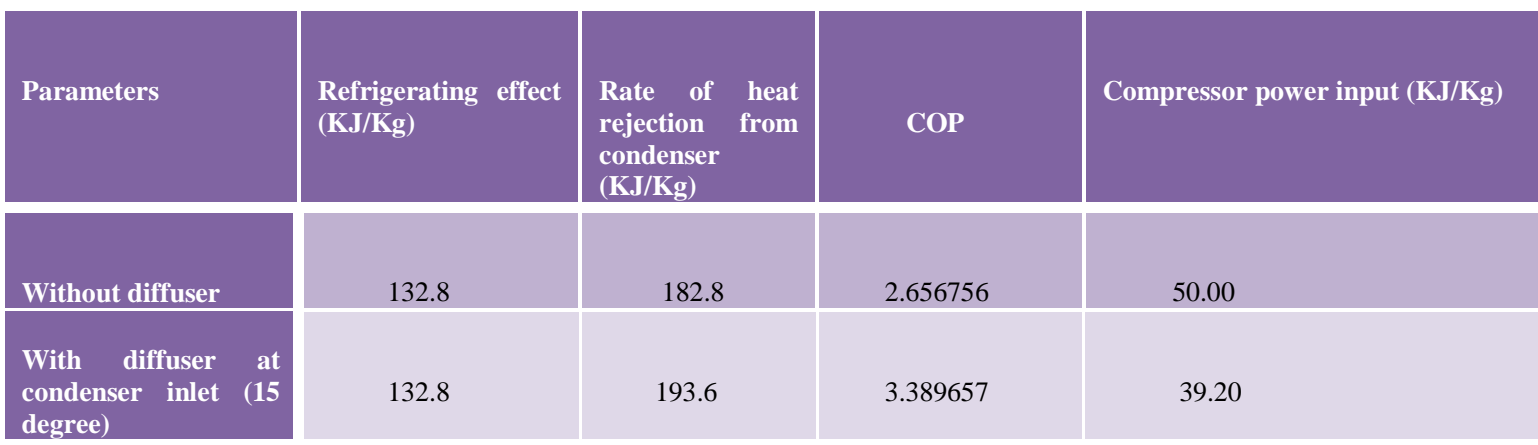

Table 2 summarizes refrigerating effect, compressor power input, COP and heat rejection rate for without and with diffuser condition.

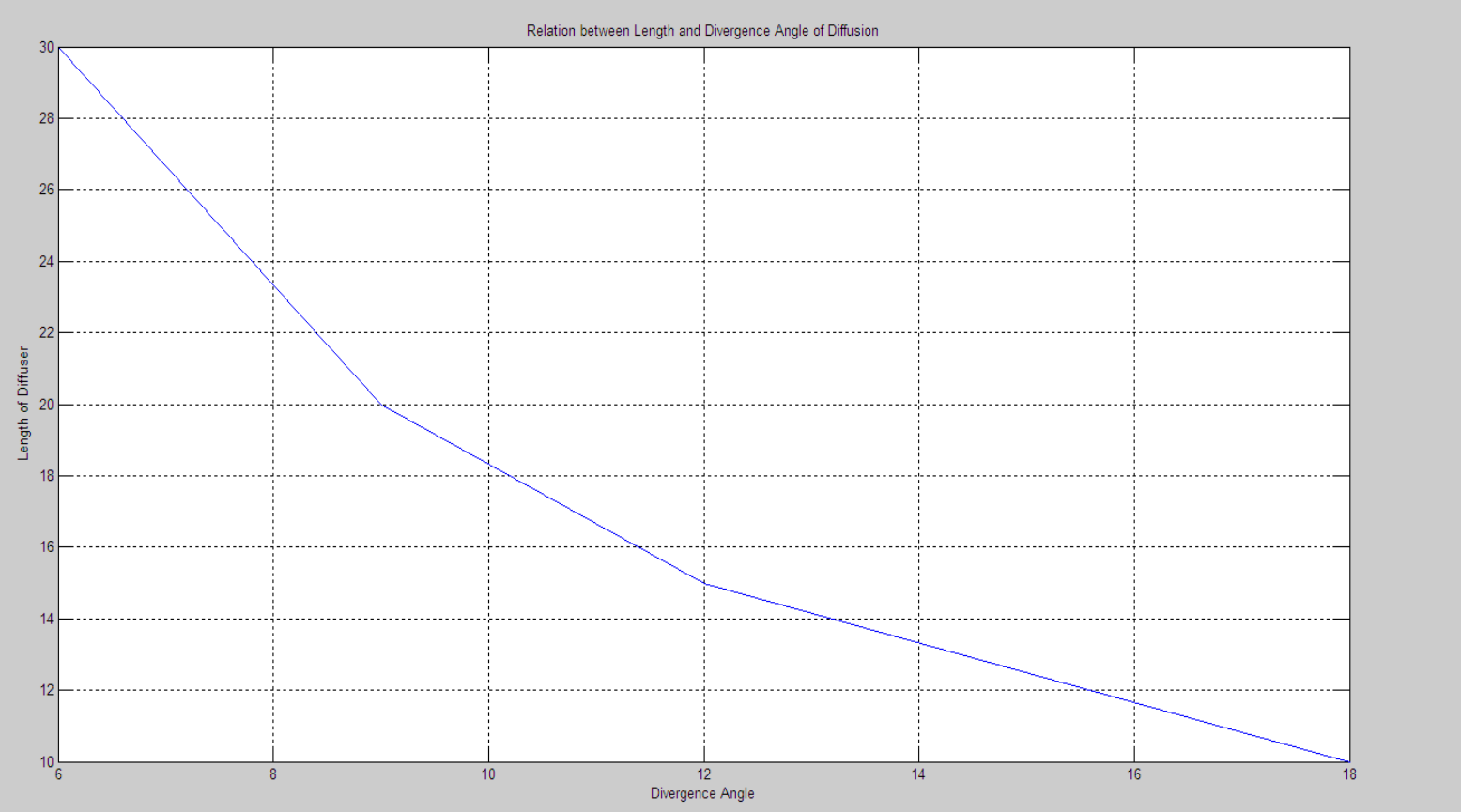

Figure 5: Relation between length and divergence angle of diffuser 
Relation between length and divergence angle of diffuser plotted as shown in Figure 2. With increase in divergence angle of diffuser, its length is reduced for same inlet and outlet diameters.

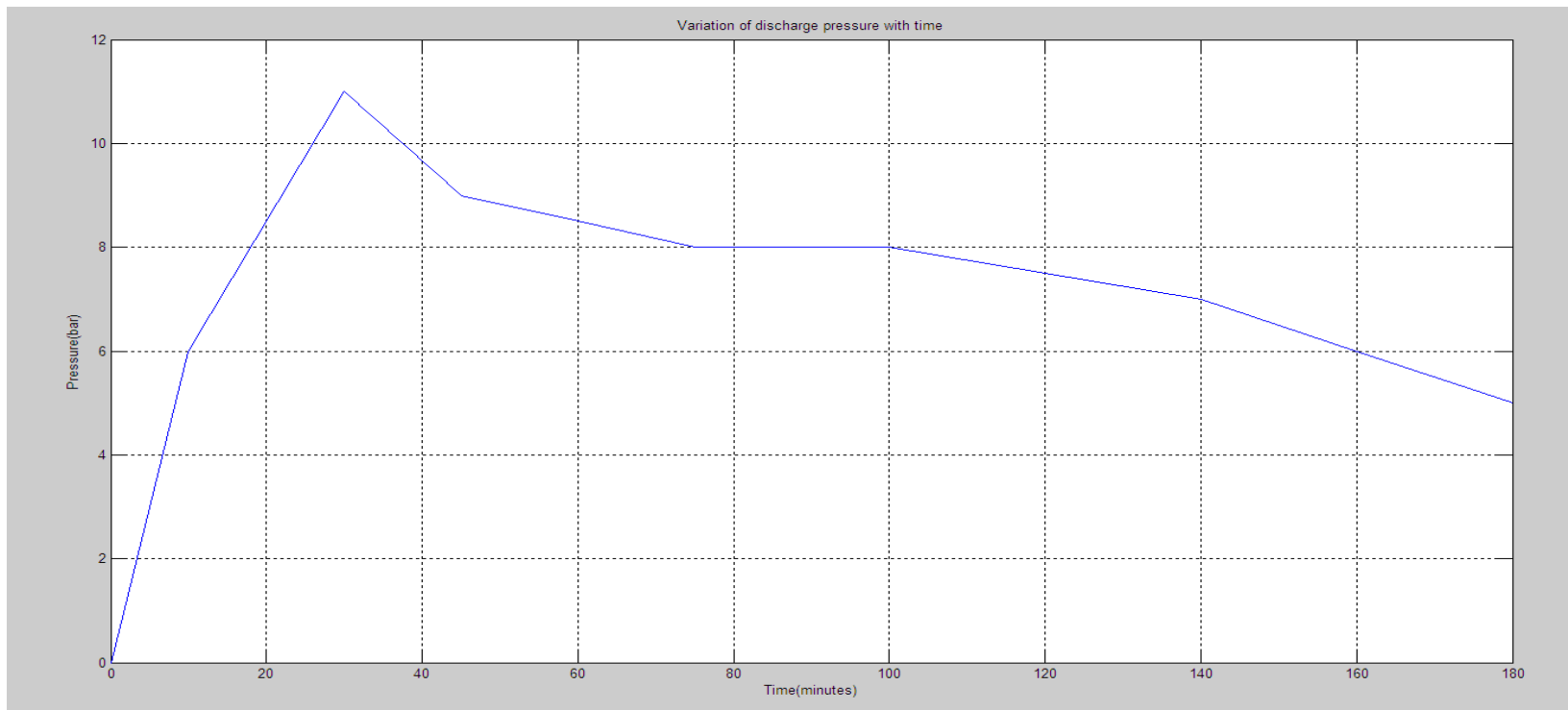

Figure 6: Variation of discharge pressure with time

Figure 5 shows the variation of discharge pressure with time. As shown in the Figure 5, the maximum shorttime discharge pressure within the first 20 min of starting the compressor runs up to 18.95 bar, after which the pressure reduced and stabilized.

\section{Conclusion}

Various set of conclusions that are derived at the end of the work are as follows:

(a) COP of VCR System has been compared with and without diffuser.

(b) It has been observed that COP with diffuser along with sub-cooling has been increased by $27.58 \%$. Rate of heat rejection is also increased due to the increase in temperature.

(c) Condenser tubes have been saved from vibration pitting and erosion.

(d) It saves from the phenomenon of liquid hump.

(e) It saves condenser tubes from undesirable splashing.

(f) Size of condenser will be reduced.

\section{References}

[1] website: http://en.wikipedia.org/wiki/Vapor-compression_refrigeration

[2] M Yari and M Sirousazar, Performance analysis of the ejector-vapour compression refrigeration cycle, Part A: Journal of Power and Energy, Vol. 221, No. 8, December 2007, pp. 1089-1098

[3] A. Selvaraju, A. Mani, Analysis of an ejector with environment friendly refrigerants, Applied Thermal Engineering, 2004, pp. 1-12

[4] Mark J. Bergander, New Regenerative Cycle for Vapour Compression Refrigeration, Final Scientific Report, DOE Award Number: DEFG36-04GO14327, 30th Sept. 2004 to 30th Sept. 2005.

[5] M. A. Akintunde, Validation of vapour compression refrigeration system design model, American Journal of Scientific and Industrial Research, Vol. 2, No. 4, 2011, pp. 504-510.

[6] M. A. Akintunde, Theoretical design model for vapour compression refrigeration systems, A.S.M.E., Vol. 73, No. 5, 2004, pp. 1-14

[7] Jianlin $\mathrm{Yu}$, Hua Zhao and Yanzhong Li, "Application of an ejector in auto cascade refrigeration cycle for the performance improvement", International journal of refrigeration, vol.31, 2008, pp.279-286.

[8] Yinhai Zhu and Peixue Jiang, "Hybrid vapor compression refrigeration system with an integrated ejector cooling cycle" International journal of refrigeration, vol.35, 2012, pp.68-78.

[9] N.D. Banker, P. Dutta, M. Prasad and K. Srinivasan, "Performance studies on mechanical+ adsorption hybrid compression refrigeration cycles with HFC 134a", International journal of refrigeration, vol.31, 2008, pp.1398-1406.

[10] Andrea Chesi, Giovanni Ferrara, Lorenzo Ferrari and Fabio Tarani " Suitability of coupling a solar powered ejection cycle with a vapour compression refrigerating machine" Applied Energy, vol.97, 2012, pp.374-383.

[11] A. Selvaraju and A. Mani, "Experimental investigation on R134a vapor ejector refrigeration system", International Journal of Refrigeration, Vol.29 (2006) pp.1160-1166.

[12] L. Kairouani, M. Elakhdar, E. Nehdi and N. Bouaziz, "Use of ejectors in a multi-evaporator refrigeration system for performance enhancement", International Journal of Refrigeration, Vol.32 (2009), pp.1173-1185.

[13] F. W. Yu and K. T. Chan, "Application of Direct Evaporative Coolers for Improving the Energy Efficiency of Air-Cooled Chillers", A.S.M.E., Vol. 127, August 2005, pp. 430-433.

[14] P N Ananthanarayanan. Basic Refrigeration and Air Conditioning. Tata McGraw-Hill, 2005.

[15] R. J. Dossat and T. J. Horan.Principles of Refrigeration, Prentice-Hall International Inc., New Jersey, USA, 2002.

[16] Yunus A. Cengel and Michael A. Boles. Thermodynamics An Engineering Approach. Tata McGraw-Hill, 2003.

[17] C. O. Adegoke and M. A. Akintunde, An Experimental Study of Hunting in Evapourators, A.U. J.T., Vol. 10, No. 1, Jul.-2006, pp. 45-51 